\title{
A harmonic suppression and size-reduced rat-race hybrid coupler using dual coupled-lines
}

\author{
Wei Song ${ }^{a)}$, Hiroyuki Deguchi, and Mikio Tsuji \\ High-Frequency Engineering Laboratory, Department of Electronics Faculty of \\ Science and Engineering, Doshisha University \\ 1-3 Miyakodani, Tatara, Kyotanabe, Kyoto 610-0321, Japan \\ a)songwei7899@163.com
}

\begin{abstract}
A newly proposed coupled-line low-pass filter structure is firstly integrated into rat-race coupler design in this paper for size reduction and harmonic suppression. This low-pass filter is composed of dual parallel coupled-lines with one open stub at the end. By properly substituting this low-pass filter unit cell (LUC) for each one of the six $\lambda / 4$ sections in the conventional rat-race coupler, significant size reduction and harmonic suppression can be achieved while the property of this proposed coupler remains comparable to the conventional one for the passband $\left(\mathrm{f}_{0}=0.9 \mathrm{GHz}\right.$ ) with $33 \%$ relative size. Transmission is suppressed below $-20 \mathrm{~dB}$ from $2.5 \mathrm{GHz}$ to $5.6 \mathrm{GHz}$, including the third, fourth, fifth and sixth harmonics.
\end{abstract}

Keywords: rat-race coupler, low-pass filter structure, transmissionline

Classification: Microwave and millimeter wave devices, circuits, and systems

\section{References}

[1] M. K. Mandal and S. Sanyal, "Reduced-length rat-race coupler," IEEE Trans. Microw. Theory Tech., vol. 55, pp. 2593-2598, Dec. 2007.

[2] M.-L. Chuang, "Miniaturized ring coupler of arbitrary reduced size," IEEE Microw. Wireless Compon. Lett., vol. 15, pp. 16-18, Jan. 2005.

[3] V. K. Velidi, D. K. Pandey, and S. Sanyal, "Microstrip rat-race couplers with predetermined miniaturization and harmonic suppression," $\mathrm{Mi}$ crowave Opt. Technol. Lett., vol. 52, pp. 30-34, Jan. 2010.

[4] W. Shao, J. He, and B.-Z. Wang, "Compact rat-race ring coupler with capacitor loading," Microwave Opt. Technol. Lett., vol. 52, pp. 7-9, Jan. 2010.

[5] H.-S. Lee, K. Choi, and H.-Y. Hwang, "A harmonic and size reduced ring hybrid using coupled lines," IEEE Microw. Wireless Compon. Lett., vol. 17, pp. 259-261, April 2007.

[6] Y. Wu, Y. Liu, S. Li, and C. Yu, "A new wide-stopband low-pass filter with generalized coupled-line circuit and analytical theory," Progress in Electromagnetic Research, vol. 116, pp. 553-567, 2011. 


\section{Introduction}

Due to its simplicity and high isolation between output ports, rat-race hybrid coupler is the key component in many microwave devices and millimeter applications such as power amplifier, mixer and antenna system. However, the physical $1.5 \lambda$ circumference makes the occupied volume too large for some practical applications. Some authors $[1,2]$ dedicated themselves into the size reduction research, but the importance of the harmonic suppression was ignored. To realize both harmonic suppression and size reduction, some attempts [3, 4] were made. In [3], though great size reduction was achieved and the band-rejection response was wide, the lower harmonic suppression should be further improved and the depth of harmonic suppression was merely below

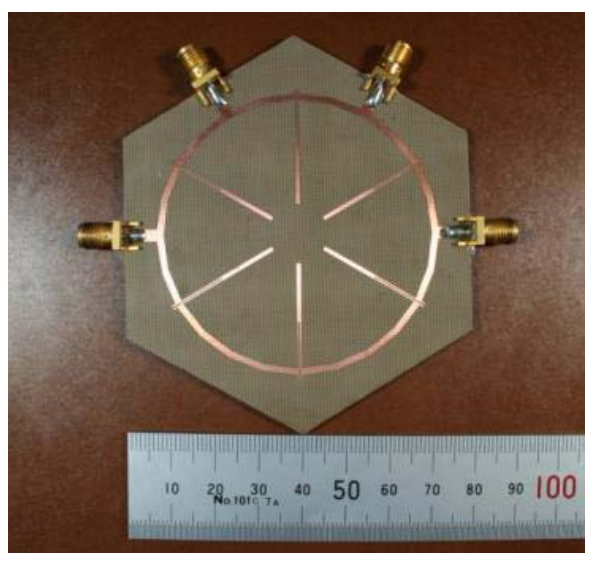

(a)

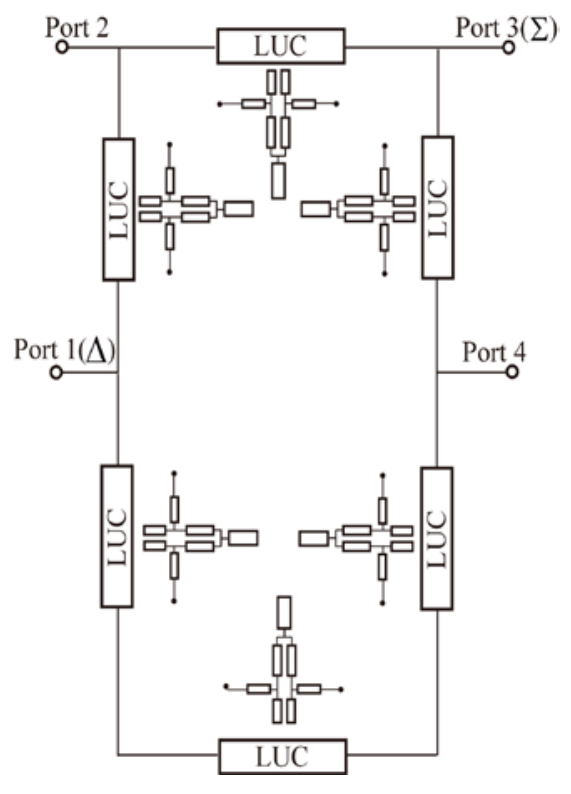

(b)

LUC

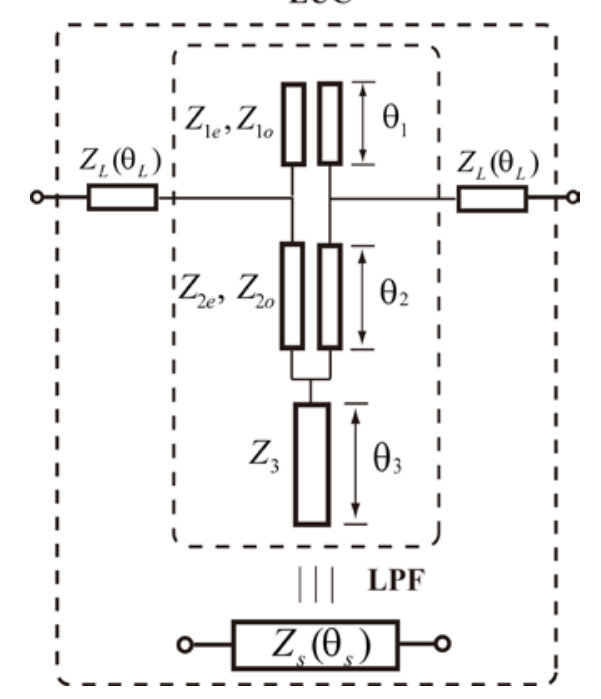

(c) 
$-15 \mathrm{~dB}$ in the stopband. In [4], the harmonic suppressed was very limited, just the second and third.

In order to achieve great size reduction and harmonic suppression, simultaneously, a new low-pass filter (LPF) unit cell (LUC) is integrated into rat-race coupler design. Compared with [5], the LPF unit cell used in this paper is generalized because LPF unit cell used in [5] is just a special case. The prototype of the LPF was originally used to design a wide-stopband low-pass filter with three transmission zeros [6]. LPF is connected with two sections of transmission-line at the end as a low-pass unit cell (LUC) so that it can be equivalent to a $\lambda / 4$ transmission-line with $70.7 \Omega$ characteristic impedance. Then, by replacing each of the six $\lambda / 4$ transmission-line sections of a conventional rat-race coupler with designed LUC, great size reduction and harmonic suppression can be achieved from the coupled-line structure and band-rejection response, as shown in Fig. 1 (a).

\section{Design theory}

The configuration of the designed coupler is shown in Fig. 1 (b). Each of the six $\lambda / 4$ transmission-lines of conventional rat-race coupler is replaced by the proposed LUC. To make the LUC appropriate for rat-race coupler design, the key work is how to design a LUC with $70.7 \Omega$ input and output impedance and $90^{\circ}$ phase shift. The LUC is composed of a LPF connected with two small sections of transmission-line $\left(\theta_{\mathrm{L}}\right)$ with characteristic impedance $\mathrm{Z}_{\mathrm{L}}$ at the end, as shown in Fig. 1(c). The LPF structure can be equivalent to a section of transmission-line $\left(\theta_{\mathrm{S}}\right)$ with characteristic impedance $\mathrm{Z}_{\mathrm{s}}$. Therefore, the total electrical length of the LUC is $2 \theta_{\mathrm{L}}+\theta_{\mathrm{s}}$, equivalently.

According to [6], the analytical mathematical equations for the LPF in Fig. 1 (c) can be expressed as $\mathrm{S}_{11}=\mathrm{R}_{\mathrm{S} 11}+\mathrm{j} \mathrm{X}_{\mathrm{S} 11}, \mathrm{~S}_{21}=\mathrm{R}_{\mathrm{S} 21}+\mathrm{j} \mathrm{X}_{\mathrm{S} 21}$

$$
\begin{aligned}
R_{S 11}=-\frac{1}{2}\left\{\frac{\left(\left\{\begin{array}{l}
Z_{0} Z_{1 e}\left[Z_{2 e} T_{3}+2 Z_{3} T_{2}\right] \\
-Z_{o} Z_{2 e} T_{1}\left[Z_{2 e} T_{2} T_{3}-2 Z_{3}\right]
\end{array}\right\}^{2}-\left\{Z_{1 e} Z_{2 e}\left[Z_{2 e} T_{2} T_{3}-2 Z_{3}\right]\right\}^{2}\right.}{\left\{\left(\begin{array}{l}
Z_{o} Z_{1 e}\left[Z_{2 e} T_{3}+2 Z_{3} T_{2}\right] \\
-Z_{o} Z_{2 e} T_{1}\left[Z_{2 e} T_{2} T_{3}-2 Z_{3}\right]+\left\{Z_{1 e} Z_{1 e}\left[Z_{2 e} T_{2} T_{3}-2 Z_{3}\right]\right\}^{2}
\end{array}\right)\right\}^{2}}\right. \\
\left.+\frac{\left\{Z_{o}\left[Z_{1 o}-Z_{2 o} T_{1} T_{2}\right]^{2}-\left[Z_{1 o} Z_{2 o} T_{2}\right]^{2}\right\}}{\left\{Z_{o}\left[Z_{1 o}-Z_{2 o} T_{1} T_{2}\right]\right\}^{2}+\left[Z_{1 o} Z_{2 o} T\right]^{2}}\right\}
\end{aligned}
$$

Where $\left(T i=\tan \left(\theta_{\mathrm{i}}\right)\right)$

$$
X_{S 11}=Z_{0}\left\{\frac{\left(\begin{array}{l}
Z_{1 e} Z_{2 e}\left[Z_{2 e} T_{2} T_{3}-2 Z_{3}\right] \\
\left\{Z_{1 e}\left[Z_{2 e} T_{3}+2 Z_{3} T_{2}\right]-Z_{2 e} T_{1}\left[Z_{2 e} T_{2} T_{3}-2 Z_{3}\right]\right\}
\end{array}\right)}{\left(\begin{array}{l}
\left\{Z_{1 e} Z_{2 e}\left[Z_{2 e} T_{2} T_{3}-2 Z_{3}\right]\right\}^{2} \\
+\left\{Z_{o} Z_{1 e}\left[Z_{2 e} T_{3}+2 Z_{3} T_{2}\right]-Z_{o} Z_{2 e} T_{1}\left[Z_{2 e} T_{2} T_{3}-2 Z_{3}\right]\right\}^{2}
\end{array}\right)}\right.
$$




$$
\begin{aligned}
& \left.+\frac{Z_{1 o} Z_{2 o} T_{2}\left[Z_{1 o}-Z_{20} T_{1} T_{2}\right]}{\left[Z_{1 o} Z_{2 o} T_{2}\right]^{2}+\left\{Z_{o}\left[Z_{10}-Z_{2 o} T_{1} T_{2}\right]\right\}^{2}}\right\} \\
& R_{S 21}=-\frac{1}{2}\left\{\begin{array}{l}
\left(\begin{array}{l}
\left\{\begin{array}{l}
\left\{Z_{0} Z_{1 e}\left[Z_{2 e} T_{3}+2 Z_{3} T_{2}\right]\right. \\
-Z_{o} Z_{2 e} T_{1}\left[Z_{2 e} T_{2} T_{3}-2 Z_{3}\right]
\end{array}\right\}^{2} \\
-\left\{Z_{1 e} Z_{2 e}\left[Z_{2 e} T_{2} T_{3}-2 Z_{3}\right]\right\}^{2}
\end{array}\right)^{2} \\
\left.\left\{\begin{array}{l}
Z_{o} Z_{1 e}\left[Z_{2 e} T_{3}+2 Z_{3} T_{2}\right] \\
-Z_{o} Z_{2 e} T_{1}\left[Z_{2 e} T_{2} T_{3}-2 Z_{3}\right]
\end{array}\right)\right\}^{2} \\
+\left\{Z_{1 e} Z_{1 e}\left[Z_{2 e} T_{2} T_{3}-2 Z_{3}\right]\right\}^{2}
\end{array}\right. \\
& \left.-\frac{\left\{Z_{o}\left[Z_{1 o}-Z_{2 o} T_{1} T_{2}\right]^{2}-\left[Z_{1 o} Z_{2 o} T_{2}\right]^{2}\right\}}{\left\{Z_{o}\left[Z_{1 o}-Z_{2 o} T_{1} T_{2}\right]\right\}^{2}+\left[Z_{1 o} Z_{2 o} T_{2}\right]^{2}}\right\} \\
& X_{S 21}=Z_{0}\left\{\frac{\left(\begin{array}{l}
Z_{1 e} Z_{2 e}\left[Z_{2 e} T_{2} T_{3}-2 Z_{3}\right] \\
\left\{Z_{1 e}\left[Z_{2 e} T_{3}+2 Z_{3} T_{2}\right]-Z_{2 e} T_{1}\left[Z_{2 e} T_{2} T_{3}-2 Z_{3}\right]\right\}
\end{array}\right)}{\left(\begin{array}{l}
\left\{Z_{1 e} Z_{2 e}\left[Z_{2 e} T_{2} T_{3}-2 Z_{3}\right]\right\}^{2} \\
+\left\{Z_{o} Z_{1 e}\left[Z_{2 e} T_{3}+2 Z_{3} T_{2}\right]-Z_{o} Z_{2 e} T_{1}\left[Z_{2 e} T_{2} T_{3}-2 Z_{3}\right]\right\}^{2}
\end{array}\right)}\right. \\
& \left.-\frac{Z_{1 o} Z_{2 o} T_{2}\left[Z_{1 o}-Z_{20} T_{1} T_{2}\right]}{\left[Z_{1 o} Z_{2 o} T_{2}\right]^{2}+\left\{Z_{o}\left[Z_{10}-Z_{2 o} T_{1} T_{2}\right]\right\}^{2}}\right\}
\end{aligned}
$$

To achieve $S_{11}=0$ for the low frequencies and $S_{21}=0$ for the high frequencies, four special frequencies including $f_{0}, f_{1}, f_{2}, f_{3}$ are defined. The frequency $\mathrm{f}_{0}$ is the reflection zero in the low frequency. The frequency point $f_{i}(i=1,2,3)$ corresponds to transmission zeros for the high frequencies. For verification, the illustration about the four special frequencies is presented in the simulated scattering parameters in Fig. 2. All the electrical lengths of coupled lines and transmission lines are specified at $0.9 \mathrm{GHz}$. As shown in Fig. 2 (a) and (b), the stopband frequency $\mathrm{f}_{2}$ monotonically decreases as $\theta_{1}$ and $\theta_{2}$ increases. However, the reverse phenomenon can be observed in Fig. 2 (c). Totally, the variation trend for both $\mathrm{f}_{0}$ and $\mathrm{f}_{3}$ is not obvious in Fig. $2(\mathrm{~d})-(\mathrm{h})$. The frequencies $\mathrm{f}_{1}$ and $\mathrm{f}_{2}$ will move together as $\mathrm{Z}_{20}$ increases, as presented in Fig. 2 (g) [6]. Since different electrical parameters respond to different special frequency point $\mathrm{f}_{0}, \mathrm{f}_{1}, \mathrm{f}_{2}, \mathrm{f}_{3}$, numerous solutions exist for the LPF design.

Considering both the widest stop band and the smallest reflection loss, 


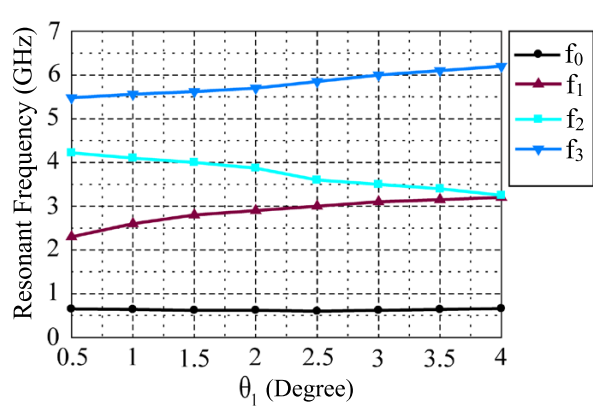

(a)

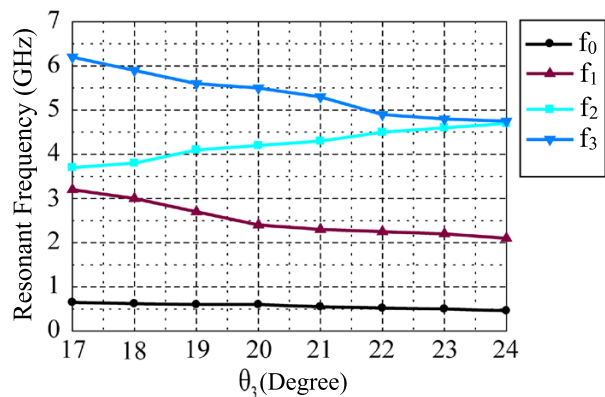

(c)

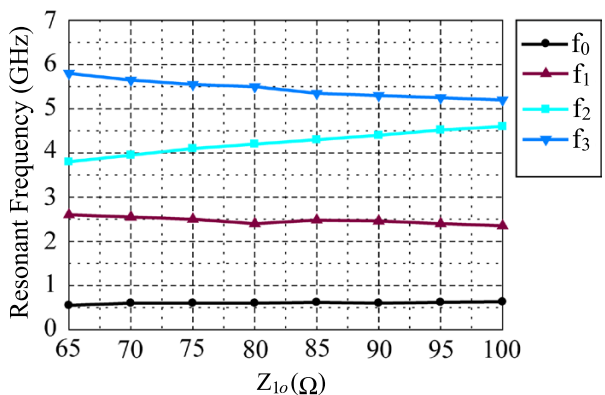

(e)

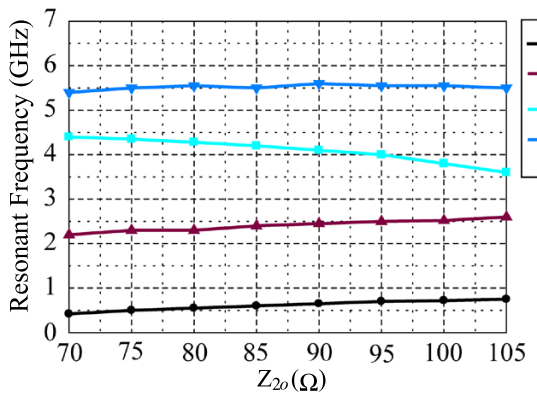

(g)

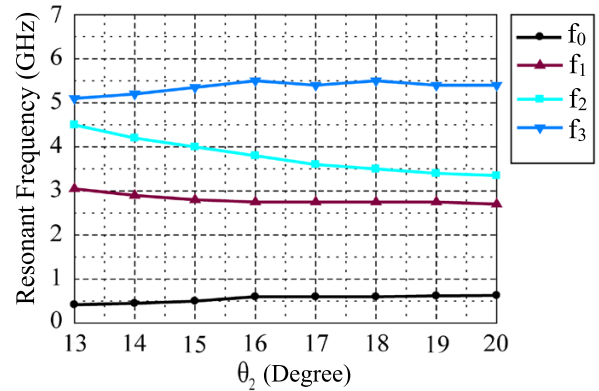

(b)

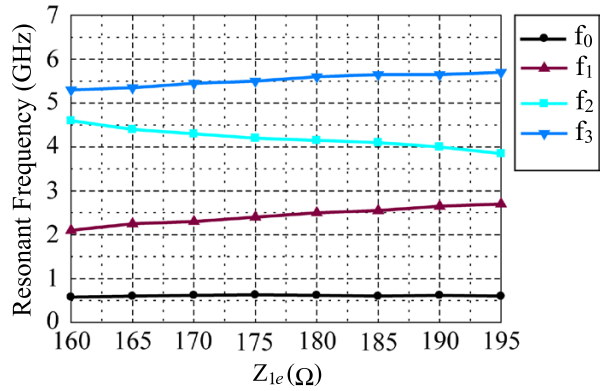

(d)

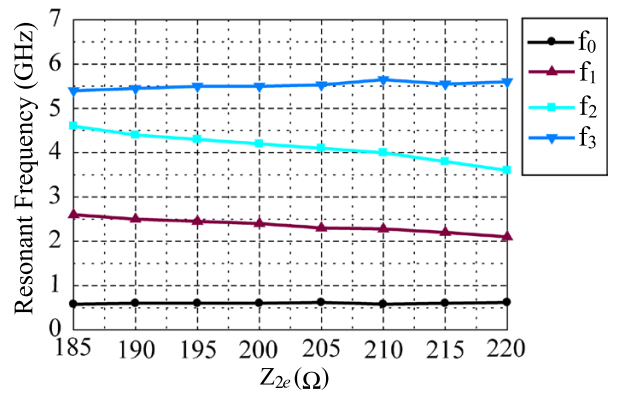

(f)

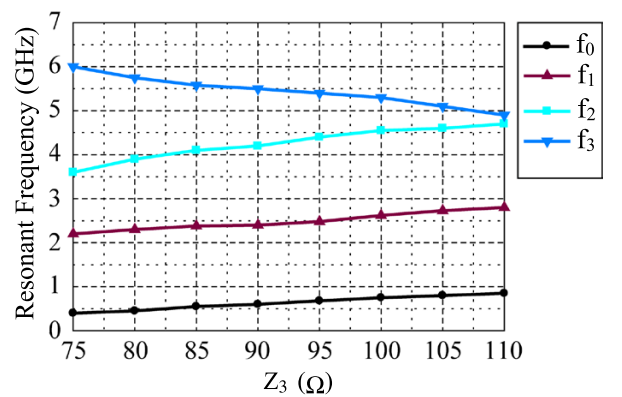

(h)

Fig. 2. Variation of $f_{0}, f_{1}, f_{2}, f_{3}$ according to (a) $\theta_{1}$ (b) $\theta_{2}$ (c) $\theta_{3}$ (d) $\mathrm{Z}_{1 \mathrm{e}}$ (e) $\mathrm{Z}_{1 \mathrm{o}}$ (f) $\mathrm{Z}_{2 \mathrm{e}}$ (g) $\mathrm{Z}_{2 \mathrm{o}}$ and (h) $\mathrm{Z}_{3}$.

the chosen electrical parameters of the LUC are $\theta_{1}=1.5 \mathrm{deg}, \theta_{2}=15.8 \mathrm{deg}$, $\theta_{3}=25.5 \mathrm{deg}, \mathrm{Z}_{1 \mathrm{e}}=172 \Omega, \mathrm{Z}_{1 \mathrm{o}}=78 \Omega, \mathrm{Z}_{2 \mathrm{e}}=200 \Omega, \mathrm{Z}_{2 \mathrm{o}}=84 \Omega, \mathrm{Z}_{3}=89 \Omega$, $\mathrm{Z}_{\mathrm{L}}=70.7 \Omega$ and $\theta_{\mathrm{L}}=20.5 \mathrm{deg}$ respectively. The transmission characteristic of LUC is shown in Fig. $3(\mathrm{a}) . \mathrm{f}_{0}$ is set to $0.9 \mathrm{GHz}$ to meet the rat-race coupler centre frequency while $\mathrm{f}_{1}, \mathrm{f}_{2}, \mathrm{f}_{3}$ are set to $2.7 \mathrm{GHZ}, 4.2 \mathrm{GHz}$ and $5.6 \mathrm{GHz}$, respectively so that transmission is suppressed below $-20 \mathrm{~dB}$ from $2.55 \mathrm{GHz}$ to $5.6 \mathrm{GHz}$. Compared with $\lambda / 4$ microwave section at $0.9 \mathrm{GHz}$, the total electrical length of LUC is $0.15 \lambda$ ( $42 \%$ size reduction). 


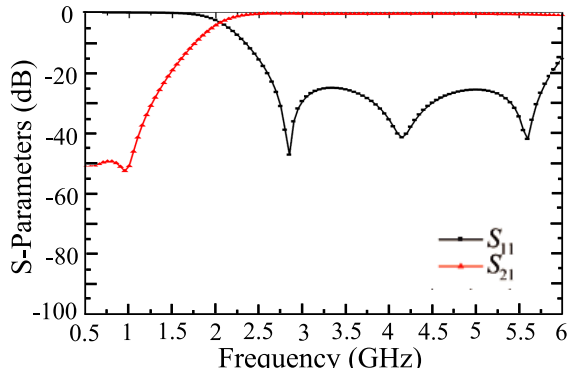

(a)

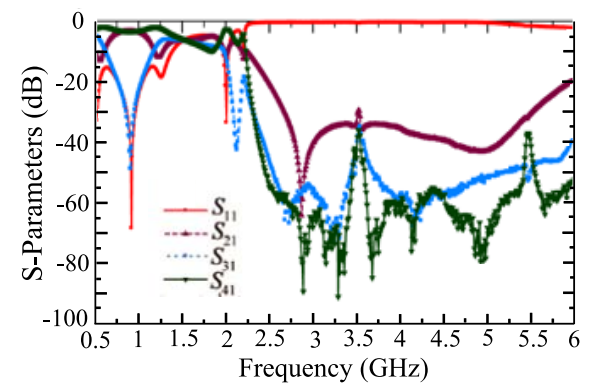

(c)

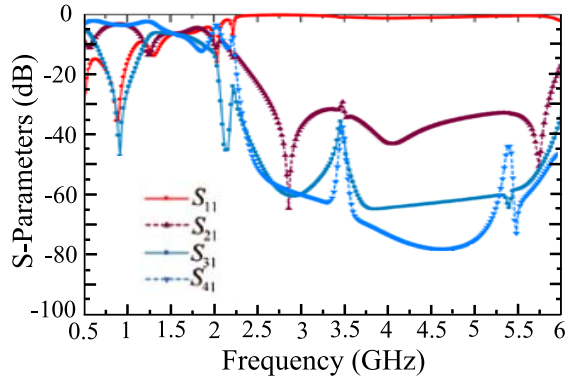

(b)

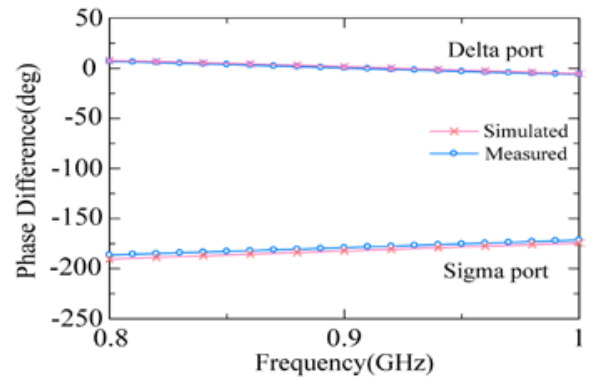

(d)

Fig. 3. Coupler design results: (a) simulated LUC design (b) simulated coupler S-parameters (c) measured coupler S-parameters and (d) phase property of Delta port and Sigma port.

\section{Simulated and measured results}

The simulated result of the designed coupler is shown in Fig. 3 (b). In the passband $\left(\mathrm{f}_{0}=0.9 \mathrm{GHz}\right)$, simulated transmissions are $-3.3 \mathrm{~dB}$ and $-3.37 \mathrm{~dB}$ at port 2 and port 4 . The isolation between port 2 and port 4 and the reflection loss are $-40.4 \mathrm{~dB}$ and $-35.4 \mathrm{~dB}$. The harmonic suppression, below $-20 \mathrm{~dB}$ is obtained from $2.5 \mathrm{GHz}$ to $5.6 \mathrm{GHz}$, including $3 \mathrm{f}_{0}, 4 \mathrm{f}_{0}, 5 \mathrm{f}_{0}$ and $6 \mathrm{f}_{0}$. To verify the simulated result, this designed coupler is fabricated on $1 \mathrm{~mm}$ substrate with relative dielectric constant 2.8. Measured result is shown in Fig. 3 (c) and (d). The centre frequency is slightly shifted to $0.91 \mathrm{GHz}$. Compared with the simulated result, the measured result agrees well with the simulated one in the power division, isolation and the impedance matching for the passband. Power division is $\mathrm{S}_{21}=-3.26 \mathrm{~dB}, \mathrm{~S}_{41}=-3.28 \mathrm{~dB}$. The isolation between port 2 and port 4 and the reflection coefficient are $-41.3 \mathrm{~dB}$ and $-37.1 \mathrm{~dB}$. Transmission is suppressed below $-20 \mathrm{~dB}$ from $2.5 \mathrm{GHz}$ to $5.8 \mathrm{GHz}$, including $3 \mathrm{f}_{0}, 4 \mathrm{f}_{0}, 5 \mathrm{f}_{0}$ and $6 \mathrm{f}_{0}$. Difference appears in the harmonic suppressed characteristic from $3.5 \mathrm{GHz}$ to $5.6 \mathrm{GHz}$. Measured result indicates transmission zero $f_{2}$ and $f_{3}$ overlap each other. This is mainly due to the fabrication error and discontinuity effect of microstrip junction. According to Fig. 2 (a) and (b), the variation of $\theta_{1}$ and $\theta_{2}$ can obviously affect the frequency point of $\mathrm{f}_{2}$ and $\mathrm{f}_{3}$. If $\theta_{1}$ and $\theta_{2}$ are shortened, $\mathrm{f}_{3}$ will shift up to higher frequency and $\mathrm{f}_{4}$ will shift down to lower frequency. Considering the discontinuity of the microstrip junction and fabrication error, the shortness of $\theta_{1}$ and $\theta_{2}$ is the main reason of the difference between the simulated and 
measured results. Good in-phase character (within $5^{\circ}$ ) for Sigma port and out-of-phase character $\left(180 \pm 5^{\circ}\right)$ for Delta port are shown in Fig. $3(\mathrm{~d})$. The area size of the fabricated coupler is $33 \%$ of a conventional one.

\section{Conclusion}

In this paper, based on a newly proposed LPF with broad stopband characteristic, a novel rat-race coupler which features great size reduction and harmonic suppression simultaneously has been proposed. The measured result indicates that in the passband $\left(\mathrm{f}_{0}=0.9 \mathrm{GHz}\right)$, it is comparable to the conventional coupler. In the stopband, transmission is suppressed below $-20 \mathrm{~dB}$ from $2.5 \mathrm{GHz}$ to $5.8 \mathrm{GHz}$, including $3 \mathrm{f}_{0}, 4 \mathrm{f}_{0}, 5 \mathrm{f}_{0}, 6 \mathrm{f}_{0}$. The occupied area of this hybrid coupler is $33 \%$ of a conventional one. As on via holes or lumped elements are involved in the design, it is easy to fabricate and cost effective. 